\title{
Child's Development and Respiratory System Toxicity
}

Rami Saadeh* and James Klaunig

Environmental Health, Indiana University, USA

\begin{abstract}
Contrary to the old saying, children are not small adults. Children are different from adults in their response to environmental stressors because of their special body composition, which continuously changes as they grow. Children's development at each stage of their life needs special consideration, especially that harmful exposures might impact their normal development, and increases their susceptibility to diseases later in life. This paper reviews children's biological characteristics, and their normal developmental changes that make them more susceptible to environmental exposures. The paper will also discuss ways in which this normal development is influenced by environmental toxicants especially early life exposures, as well as the possibility of disease development. In this review, asthma is used as an example of a respiratory disease influenced by environmental toxicants, and methods of risk assessment used to predict such a disease are discussed.
\end{abstract}

Keywords: Toxicity; Respiratory; Risk assessment

\section{Growth in Childhood}

Humans grow slower than many other species. A lot of growth and weight gain happen during childhood, and specifically during the first two years of age. Humans reach $70 \%$ of their adulthood height at the age of six. Growth accelerates during certain periods of childhood known as growth spurts. These growth spurts happen six times through childhood which are; neonatal, infantile, early childhood, middle childhood, late childhood, and pubertal period [1]. Yet, growth during each of these growth peaks varies remarkably among individuals, mainly due to the integrative and mixed influence of cultural, behavioral, nutritional, genetic, and environmental factors. General body growth (i.e. weight and height) differs from internal organs growth. Human organs grow at different rates because cell divisions in these organs vary in time and pattern. While the liver and kidneys grow fast throughout childhood, the brain has shown minimal weight increase from childhood to adulthood. Growth of adipose tissues and muscles in childhood is not as fast as it is in teenage and adult years. The Lungs grow and gain weight faster than the kidneys, but slower than the liver [2,3].

\section{Physiological and Anatomical Development}

Children breathe at a faster rate than adults. This is because the number of alveoli in infants and children are less than those in Adults. Alveoli in children are also smaller in size than adults; therefore children need higher ventilation rate to meet the oxygen requirement of the body. With normal growth during the first few years of life, the size and weight of the lung increases, the ratio of ventilation rate to lung surface is relatively larger in infants and children compared to adults. Higher ventilation rate in children makes particles move faster along the respiratory tract and spend less time in any designated area of the lung. This faster movement and less residential time allow these particles to penetrate deeper in the lung, representing them more into the alveolar blood: air barrier [4]. The deeper penetration increases the dose absorbed in children. Other factors which assist such penetration are cardiac output, physical activity, and mouth to nose breathing ratio. Higher mouth to nose breathing ratio raises the chance of a deeper penetration because the mouth has a smaller surface area for the deposition of particles, and thus, more particles move into the lungs compared to particles coming in through the nose [4]. Physical activity in children is another factor contributing to increased ventilation rate which increases the inhalation of particles and vapors. In addition to that, physical activity increases mouth breathing during moderate to heavy exercises. One study found increased mouth breathing by $20 \%$ in children aged 8-16 years while performing a physical activity [5]. It's not yet clear when switching from nose to mouth breathing during exercise happens in children. However, it was found that switching in adults happens when inhalational rate reaches $15 \mathrm{~L} / \mathrm{min}$ [4]. The different patterns of nasal structural development among children also affect the inhalation and deposition rate of particles. The structure of the nose in children allows lower nasal filtration rate and higher nasal airway resistance. These two factors increase mouth to nose breathing ratio and further the penetration of particles into deeper parts of the lower respiratory tracts $[5,6]$, and probably cause a higher nasal deposition rate [7]. Deposition also varies with variations in breathing patterns. Variations of breathing patterns include fluctuations in tidal volume and breathing rates during childhood $[8,9]$. Cardiac output decreases as age increases; adults have a lower cardiac output compared to children. Ventilation rate, size of the body, metabolic rate, and physical activity are factors affecting the cardiac output. All of these variables are higher in children compared to adults, which leads to a higher cardiac output. A higher cardiac output allows for rapid delivery and exchange of substances between the blood and different body tissues. This delivery is enhanced for the free un-bounded circulating chemicals, which are not bound to plasma binding proteins. This too is higher in children in comparison to adults due to the lower amounts of such binding proteins as well as their functional immaturity [10]. Chemicals that don't bind or conjugate to any plasma proteins are either metabolized or eliminated. Such elimination processes are less efficient in children due to their lower glomerular filtration rate and lower renal clearance efficiency in the first six months of age [11].

\section{Metabolism and Maturity of Metabolic Processes}

The metabolic abilities in children are different than those in adults. The metabolic differences make them less susceptible to environmental

*Corresponding author: Rami Saadeh, Environmental Health, Indiana University, USA, Tel: 973-495-0570; E-mail: rsaadeh@umail.iu.edu

Received May 16, 2014; Accepted July 09, 2014; Published July 16, 2014

Citation: Saadeh R (2014) Child's Development and Respiratory System Toxicity. J Environ Anal Toxicol 4: 233. doi: 10.4172/2161-0525.1000233

Copyright: (c) 2014 Saadeh R. This is an open-access article distributed under the terms of the Creative Commons Attribution License, which permits unrestricted use, distribution, and reproduction in any medium, provided the original author and source are credited. 
toxins in some instances or more susceptible in others. It's thought that children have less metabolic capacity than adults that don't reach its full capacity until early adulthood [12] Children's lower metabolic abilities reflect either negatively or positively on them. It can be protective to a child if the body cannot process a substance into its toxic metabolites. On the other hand, the inability to metabolize a toxic parent compound into less toxic substances can be devastating [13].

The immaturity of metabolic enzymes might result in low clearance levels [14]. Enzymes including oxidases, reducates, and hydroxylases have their initial development little after birth and continue to develop until full maturity is reached, several months after birth. On the other hand, most of other metabolizing enzymes develop approximately in the middle of the gestational period, and become fully functional few months after birth. One example of late development is the synthesis and function of the oxidative demethylation enzyme; it is synthesized a few months after birth, and reaches its full functional capacity when a child reaches the age of two.

Children tend to have higher metabolic rates than adults due to their high cardiac output high ventilation rate, and high physical activity. In addition to that, children grow fast and increase in size. Resting metabolic rates and oxygen consumption are higher in infants and young children in comparison to adolescents and adults. This can be explained by their fast growth and higher inhalation rates per unit of body weight. Another factor affecting resting metabolic rate is body mass index (BMI). Children with increased BMI tend to have higher resting metabolic rates compared to children with lower BMIs of the same age [15].

Unfortunately, data on environmental toxicants metabolism in children are very limited, and more data are available for medicinal drugs. On the other hand, there is a wealth of data on adult's metabolism of drugs and environmental toxins. Such data on drugs' metabolism in adults and in children help make comparisons between half-life of drugs in children and in adults. One of the studies which compared neonates' and adults' drug metabolism showed that some drugs have half-time of metabolism in full-term neonates up to three to nine times more than in adults; the database included 45 drugs. This difference decreases after two to six months of age, but appears back during adulthood for certain drugs. In general, drugs used in adults have a shorter half-life for certain drugs and pathways [14]. A good example which elucidates the difference in the metabolism of chemicals between adults and children is caffeine. Caffeine's main metabolizing enzyme is CYP1A2 [11]. Cytochrome P450 is a wide and diverse group of enzymes responsible for a vast majority of metabolic reactions in the body during phase 1 metabolism. It changes the chemical (natural or synthetic) into a more hydrophilic metabolite which can be readily eliminated [16]. CYP1A2 starts the catalysis of caffeine by an $\mathrm{N}$-demethylation reaction, followed by $\mathrm{N}$-acetylation via $\mathrm{N}$-acetyltransferase. Because CYP1A2 is immature until the age of 6 months, infants below that age can have a caffeine half-life up to 14 times greater than in adults [11]. CYP1A2 is also responsible for metabolizing theophylline. Theophylline is a drug structurally and pharmacologically similar to caffeine, used to treat respiratory diseases like asthma and chronic obstructive pulmonary disease 'COPD' [17]. Similar to caffeine, a slow metabolism of theophylline makes the halflife and the effect last longer.

After six months of an infant's age, a switch in the metabolism pattern happens to these two chemicals; causing faster metabolism and shorter half-life. This is best explained by increase in blood flow to the liver per body weight at six months of age as well as maturation of the
CYP1A2 pathway. These two factor help improve the metabolism, and this is true for many other CYP450 enzymes [11]. However, relatively shorter half-life of certain chemicals in children after six months of age raises additional challenges. For instance, if a parent compound has a faster metabolism leading to a more toxic metabolite without fast clearance of the product then greater toxicity is produced. Otherwise, if clearance is fast, then the metabolite or even the parent compound is removed fast and toxicity will be less of a concern.

Another example of a metabolic enzyme with lower function during infancy is $\mathrm{N}$-acetyltransferse, which is the secondary enzyme involved in caffeine and Theophylline metabolism. It exhibits insufficient function in infants younger 6 months of age. Epoxide hydrolase is another example, it is a detoxifying epoxide, and is also deficient in this early period [11]. These enzymes involved in phase 1 metabolism transform parent compounds to a more hydrophilic metabolite(s) ready to be conjugated to a binding protein and then eliminated. Glucuronidation-a process of attaching a substance to glucuronic acid is one way a metabolite is conjugated and transferred for elimination. Glucuronidation is found to be deficient in the first month after birth. This deficiency along with the other maturational delays mentioned above in phase 1 metabolic enzymes place the newborn infant at a higher risk for toxicity. A good example of toxicity produced by glucuronidation insufficiency is chloramphenicol accumulation. Chloramphenicol accumulates and results in anemia in infants if glucuronidation is insufficient [11]. Lack of glucuronidation and other conjugation methods adversely affects the elimination of toxic materials. Metabolism and half-life varies among children. Some studies show that variability in metabolism for many drugs is higher in children of younger ages than in adults. However, this is true for many, but not for all drugs [4]. Some anesthetic gases for example display variability in metabolism among children of different ages. The variation in manifested by a variation of binding factors in the blood which in turn make differences in partition coefficients of the gases. Such differences in partition coefficient were not found in adults [4] Proteins such as albumin and alpha-1- glycoproteins binding proteins show lower serum levels in infants in comparison to later childhood and adulthood. The levels of these proteins can also influence the metabolism of drugs and chemicals [10]. Albumin binds to acidic chemicals, whereas alpha-1-glycoproteins bind to basic chemicals. The lower levels of these binding proteins causes more free chemical compounds ready to be taken up by the cells and can result in toxic effects. Nevertheless, non-binding is beneficial for chemicals that don't have high tendency for plasma protein binding because it exposes chemicals for metabolism and elimination $[11,10]$.

\section{Toxicokinetics and Toxicodynamics in Children}

Toxicokinetics (TK) is the process of absorption, metabolism, distribution, and elimination. TK in children is different than in adults due to the continuous growth in children's respiratory system, their physical activity, and their body weight. For example, the exposure to an ultrafine particulate matter of air pollutant can be two to four times higher in a three-month old child than in an adult, as a result of lung deposition and body size factors [4]. Drug or 'toxins' metabolismas discussed in the metabolism section-take longer in children than in adults. Therefore, the half-life of substances is longer in children, and their elimination rate is slower. Based on the half-life of some substances, hepatic and renal functions are considered to be at a lower functional rate than in adults for all chemicals' types: organic, lipophilic, hydrophilic, and ionic [18]. This leads to a longer time for elimination [19]. At the same time, having relatively less fat tissue compartment 
makes lipophilic chemicals less soluble [20] and therefore, body composition affects the distribution and deposition of chemicals. The dose distributed to the tissues of different organs is ready to be up taken by the cells. This is when an interaction between the dose and a body component happens, and this is what Toxicodynamics (TD) basically is. TD relates to the interaction of a chemical with the cellular or biological components of the body followed by a biological effect. The connection between TK and TD is shown in Figure 1.

TD shouldn't be different between children and adults if the TK differences are controlled for in the statistical analysis (i.e. doseinteraction effect and biological response should be the same if TK is controlled for). However, the same doesn't hold true for infants. Unfortunately this is difficult to test experimentally [21].

\section{Development of the Respiratory System}

Lung development is a complicated and long process which starts as early as the fourth week of gestation, and continues until the age of 20 years [22]. This long process includes the integration of a variety of regulatory factors responsible for cell proliferation, differentiation, migration, and death. These developmental and differentiation changes happen prenatally to provide the baby with a functional lung. However, a great deal of maturation and growth happens postnatally to increase the lung's size and number of branches and alveoli. Embryonic lung formation goes through five consequent stages. Each stage is characterized by its own anatomic and histologic features. Airways' formations occur in early embryonic and pseudo-glandular stages. Formation of the air-blood barrier through vascularization and reduction of mesenchyme occurs in the canalicular, saccular, and alveolar stages [23]. This development continues after birth, but mostly by increasing lung size and surface area. A neonate at birth is born with approximately 50 million alveoli, which have the ability to multifold five times to reach near 250 million later in life. The surface area is enlarged to reach up an area of $70 \mathrm{~m}^{2}$, with over forty different types of fully maturated and differentiated cells in the lung [24].

\section{Respiratory Developmental Susceptibility}

Inter-species and intra-species differences have been apprehended and handled in the process of risk assessment a long time ago. The extrapolation from animals to humans is a common procedure in risk assessment since most of toxicological studies are done on animals. Relevant estimations of human exposures is assessed based on physiological and biological differences between animals and humans. Thus, estimation of a risk on humans' inhalational health occurs through extrapolating from animals to humans mainly based on differences between animals' and human's dosimetry.

Humans as a species are divided to a regular population and a

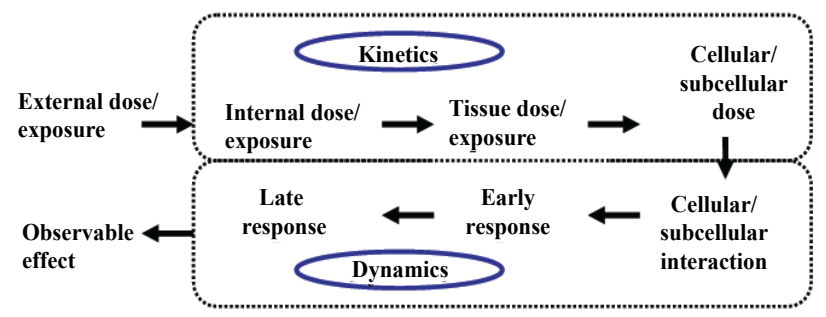

Figure 1: The connection between Toxicokinetics and Toxicodynamic (WHO) [65]. sensitive population. Children are categorized among the sensitive population. They, as a susceptible population, go through a lot of developmental changes during their growth (Figure 2), which continuously alters their susceptibility to environmental insults. Periods of susceptibility in children vary, and there are times when children are more susceptible to environmental stressors than other times.

Among different environmental stressors, air pollutants are thought to be the major chemical stressors for the respiratory system, and most likely related to the etiology of many respiratory diseases. Exposure to air pollutants during different life stages differs in concentrations based on air pollutants' concentrations; child's breathing rate, and frequency and duration of exposure.

Respiratory uptake and absorption differ among children of different ages, and differ among children of the same age. The respiratory physiological factors which differentiate children inhalational uptake and absorption rates are: ventilation rates (which lead to enhanced lung deposition), higher mouth to nose breathing rate (which increase the amount of inhaled material) decreased particular uptake from the nasal airway (which leads to higher deposition in the lower respiratory tract), and the larger deposition efficiency of some particles and vapors in the lower respiratory tract [25]. Furthermore, there are factors among children which contribute to different degree of particulate matter deposition in the child's lung. These factors include: race, obesity, and current status of the lung (the presence of respiratory disease such asthma or allergic rhinitis) [25].

\section{Periods of Susceptibility}

There are five developmental stages for respiratory system development in the fetus. Four are completed before birth, and the fifth one, which is alveolar formation, begins prenatally, but continues and expands postnatally. This means that most of the true formation of the lung system happens in the uterus, thus making this period critical in terms of susceptibility and vulnerability to external insults. Cell division and differentiation during gestation is very crucial for a normal lung development. Lung development is until the age of eight, but size increase continues until the age of 18 [26].

There are different human and animal studies tried to estimate the influence of environmental exposure during fetal life. Experimental studies on animals show that fetal exposure to environmental factors is more harmful to the fetus, prenatally than postnatally. One study done on rabbits found that an environmental exposure resulted in lung injury and impaired normal growth of the lung. Lung injury happened shortly and resulted in impairment in the lung cells' differentiation and maturation during development [27]. Another study investigated the effect of ozone on neonatal monkeys at a daily and seasonal basis. Ozone caused higher oxidative stress to exposed monkeys compared to the control. The oxidative stress injured the pulmonary gas exchange units, and therefore affected the lung functional capability [28]. Some other studies done on rats tested the effect of pre- and postnatal exposure to cigarette smoking on the functional development of the lung. The effect was an induced hyper-responsive in the respiratory tract of born rats and malfunction of their lungs $[29,30]$.

Epidemiological studies showed that air pollution has adverse health effects on the human body before a person would turn to day one of age. Mothers exposed to air pollutants were observed to carry serious effects to the fetus. Serious as it would be fatal to the fetus at an early phase of pregnancy [31], produce a preterm birth [32-34], or result in 


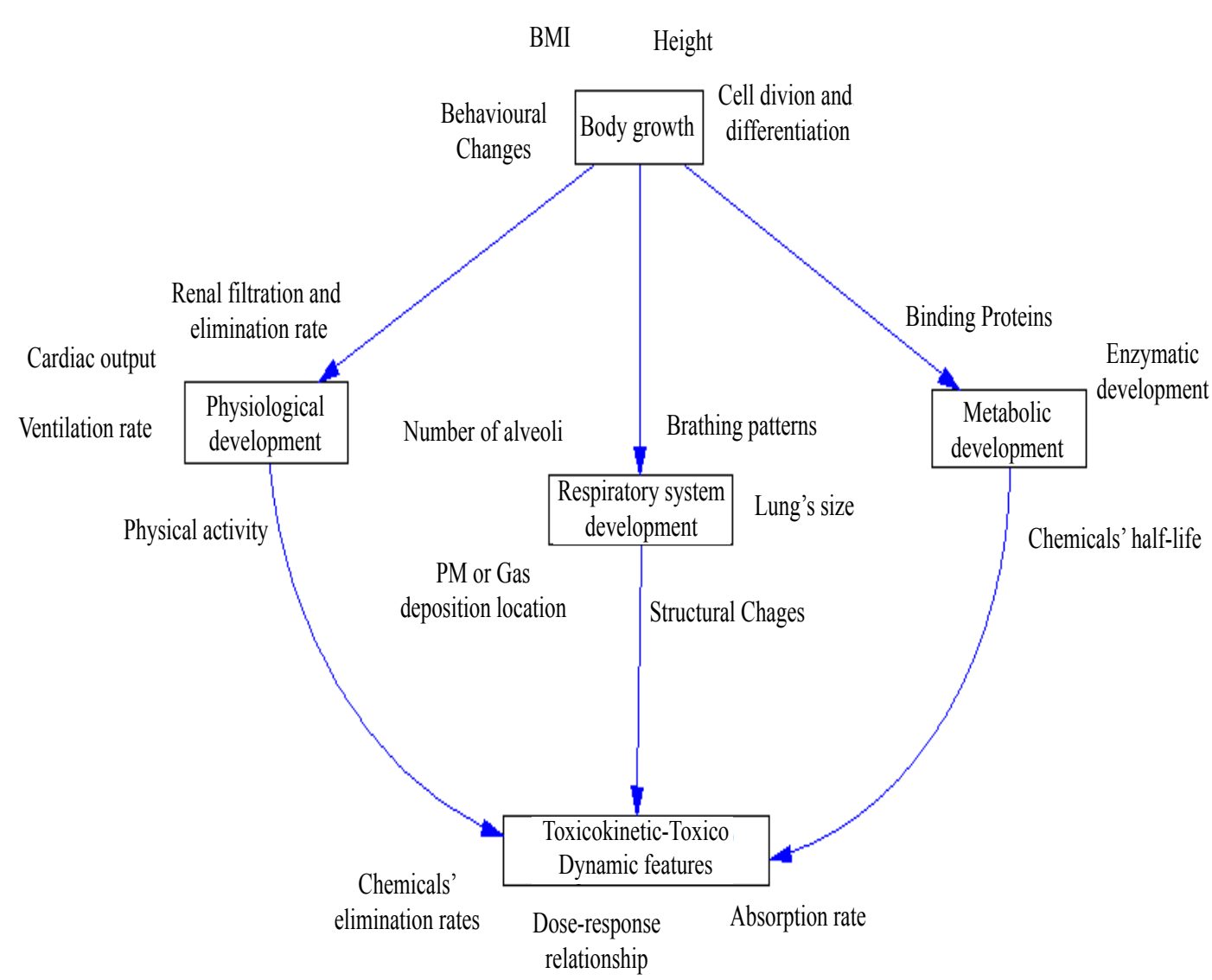

Figure 2: Variables changing over time of a child's life. Such variables differ among children of different ages, which alter children's susceptibility to environmental insults.

low-weight babies [35-40]. For instance, mothers who are smokers or mothers who are exposed to polycyclic aromatic hydrocarbons (PAH) from combustion sources, have higher tendency to deliver pre-term babies, or to deliver low birth weight babies [41-43]. Infant mortality rates are noticed to increase with increased air pollution. An example of that is London coal smoke tragedy. In 1952, a great smoke covered the atmosphere in London killing near 4000 people, most of them were adults. However, infant mortality rate was higher during this tragedy; it was doubled [44]. Air pollution in general is found to be correlated with increased infant mortality rate [45]. An increased concentration of particulate matter (PM10) in the air increased infant mortality rates for infants aged 2-12 months [46,47]. A cross-sectional study examined the reasons of respiratory illness causing infant mortality. The findings referred to the increase in air concentrations of total suspended particles (TSP) and sulfur dioxide $\left(\mathrm{SO}_{2}\right)[48,49]$.

Respiratory distress, causing infant mortality, doesn't always happen. Milder adverse health outcomes of the respiratory system happen if the exposure is at lower levels, or exposure happen on a later stage of a child's life. One example, is a study on college students found that increased risk of wheezing and chronic respiratory symptoms were noticed in young college students because of chronic exposure to ozone during their childhood, which probably affected the normal growth of their lungs [50]. Another cohort study in California associated adults' declined lung's function with exposure to nitrogen oxide, particulate matter (PM2.5), and other vapors [51]. Nonetheless, even if lung grows normally during childhood, and nothing observed to be interfering with its development, it is believed that many environmental air pollutants could provoke or accelerate the development of a respiratory disease, such as asthma or allergy any time in life. Many studies linked late childhood exposure to particulate matter, ozone, $\mathrm{NO}_{2}$, and sulfur oxides with asthma occurrence [52-55]. Although early exposure is more harmful to the lung and adversely affects its development, anytime exposures during life are still harmful and may end up in a respiratory disease, such as asthma.

\section{Asthma: A Respiratory Disease with Developmental Sensibility}

Asthma is a chronic respiratory disease, the most common chronic disease in children. It is multifactorial and complex in origin, which makes it difficult to predict when it could occur. However, asthma development has been demonstrated to be influenced by environmental stressors during early lung development. The effect of genetic background, environment, nutrition, and SES on asthma development makes it difficult to devise an accurate model that predicts its occurrence. This problem can be further complicated by the fact that both pre- and postnatal exposure to environmental stressors contribute to asthma development. A study reviewing the literature showed that prenatal exposure to smoking increases the risk of asthma in the same way as postnatal exposure increases it [56]. Unfortunately, models structured to predict asthma occurrence through the utilization of specific biomarkers are not yet available. However, several studies have utilized the physiological, biological, and immunological changes 
preceding asthma occurrence in a model to predict its occurrence in children. These changes are manifested by cellular and biochemical biomarkers identified in pathological pathways as a sign of probable asthma occurrence in the future $[57,58]$.

\section{Environmental Pollutants Linked to Asthma}

Environmental air pollutants have been associated with asthma in children. A meta-analysis study reviewed the relationship between formaldehyde and formation of asthma in children and concluded a positive relationship by an odds ratio of 1.03 (95\% CI, 1.02-1.04) for the fixed-effects model, and an odds ratio of 1.17 (95\% CI, 1.01-1.36) for the random effects model [59]. Another meta-analysis study analyzed 36 studies on particulate matter exposure and asthma occurrence in children. The analysis found a statistical significant relationship between particulate matter $\leq 10 \mu \mathrm{m}$ and asthma symptoms [odds ratio $(\mathrm{OR})=1.028 ; 95 \%$ confidence interval $(\mathrm{CI}), 1.006-1.051$ ]. Poly Aromatic Hydrocarbons 'PAHs' relation with asthma was conducted in case-control study done on Saudi children. The study considered three biomarkers related to asthma, which are IgE, resistin and IL-4. Levels of biomarkers in asthmatics were higher than non-asthmatics, levels of IgE was $(123.1 \pm 5.0$ for asthmatics vs. $61.1 \pm 4.3$ for non-asthmatics, $\mathrm{p}=0.004)$, resistin $(24.5 \pm 1.6$ for asthmatics vs. $17.3 \pm 1.3$ for nonasthmatics, $\mathrm{p}=0.001)$ and IL-4 $(18.5 \pm 3.6$ for asthmatics vs. $9.2 \pm 1.4$ for non-asthmatics, $\mathrm{p}=0.003) \mathrm{pg} / \mathrm{ml}$ [60]. Another study on particulate matter found strong association of personal elementary carbon from diesel products with asthma exacerbations in children living close to roadways [61]. Ozone has been linked to acute respiratory reactions in the children and adults, and the main respiratory reaction in children was developing asthma [62]. A Chinese study tested the concentration of black carbon and particulate matter $(\mathrm{PM}<2.5 \mu \mathrm{m})$ in air before and after the Olympics held in Beijing in 2008. The study also tested the concentration of exhaled nitric oxide in school children as a biomarker of acute inflammation in the respiratory system. Findings of the study were: an increase in children's exhaled nitric oxide by $16.6 \%[95 \%$ confidence interval (CI), 14.1-19.2\%] per interquartile range (IQR), an increase of black carbon concentration in the air to $4.0 \mu \mathrm{g} / \mathrm{m}^{3}$ or to $18.7 \%$ (95\% CI, 15.0-22.5\%) per interquartile range (IQR), an increase of particulate matter (PM2.5) concentration in the air to $149 \mu \mathrm{g} / \mathrm{m}^{3}$. These findings made the authors to conclude that a strong association between (black carbon and particulate matter) and acute respiratory inflammation exist in school children [63].

\section{Developing Models to Predict Asthma in Children}

Developing such models might not succeed in the near future because of the complex nature of the disease. However, several experimental studies tested models on animals, and investigated their applicability to humans. A study on rhesus monkeys suggested that such primates can serve as a good model to assess asthma and allergies in humans. Rhesus monkeys possess an epithelial-mesenchyme trophic unit of the lung very close in structure to that of humans [64]; furthermore, the postnatal growth pattern of the airways of the lung is similar in rhesus monkeys and humans. These similarities produced an experimental allergic reaction development in rhesus monkeys similar to those in humans [64]. Other animal models used for asthma assessment were rodent models. They are in general the most commonly used models, mostly used for dose-response relationships linking between air pollutants and respiratory illness due to initial sensitization, testing of epidemiological hypotheses, and for high to low dose extrapolation, when assessing risk in humans by using animal data [64].

\section{Using Computational Toxicology as Predictive Tools}

Challenges in predicting complex diseases such as asthma requires the use of advanced methods which have the capability to consider all factors and variables related to a certain disease so as to produce the best possible prediction. So far, computational modeling applications in toxicology and risk assessment are the most promising methods to meet the challenges. Computational methods have the ability to aggregate, analyze, and summarize large numbers of databases with huge datasets. These methods include but are not limited to database mining, molecular network analyses, read-across matrices and toxicological prediction models such as the physiological-based pharmacokinetic (PBPK) models and the quantitative structure-activity relationship (QSAR) models. These computational predictive models will support the use of a voluminous amount of toxicity data in a costeffective and comprehensive manner, produce better interpretations, and derive conclusions important for risk assessment, management and decision making.

\section{Using the PBPK Model to Predict Asthma in Children}

PBPK models are amongst the first in the literature to describe the pharmacokinetic action of drugs. Interest in these models began in the early 1970s. PBPK models are mathematically developed equations used to describe absorption, distribution, metabolism and excretion (ADME) of synthetic or natural chemicals in the human body, based on the chemical's physiological and pharmacological characteristics that can determine its effect and final elimination from the body [6570]. The advantage of PBPK models is their ability to estimate the internal tissue dose rather than predicting the dose from an external exposure concentration [69]. This adds reliability to risk assessment, and decreases uncertainty related to toxic effects. In addition, PBPK models are fairly flexible, and have the ability to be expanded and modified if more parameters have to be incorporated into them. PBPK models are very useful tools, and their ability to predict health outcomes are promising.

\section{Developing a PBPK Model for Children}

Children differ from adults in chemicals' pharmacokinetics and pharmacodynamics. The continuous growth and development of children's bodies affect their physiological, biochemical and immunological characteristics in a continuous manner. To build a PBPK model specific to children, ADME during different developmental life stages has to be considered. Initial use of PBPK models for children began in the mid-1980s in an effort to assess children's exposure to environmental toxicants [71]. Many of these models have used an earlylife stage renal clearance model to assess risk of chemicals' exposure [71]. The capability of developing a PBPK model for environmental chemicals was limited; furthermore, most of PBPK models developed for children were drug models. Some examples of drug modelling using a child-adjusted PBPK model are the modeling of theophylline and midazolam disposition in infants and children [72]. Teduglutide, an analog to glucagon-like peptide 2 , is used to enhance intestinal function by repair and regeneration, was modeled in neonates and infants [73]. Another example is the modelling of caffeine and theophylline in neonates and children [74]. PBPK models have the ability to integrate data generated from different experimental methods. This is shown in a study which used a PBPK model to predict acetaminophen metabolism and pharmacokinetics in neonates, infants, children and adolescents. The authors integrated in silico, in vitro, and in vivo pharmacokinetics data into a single PBPK model and proposed that such a model could 
predict internal dose in children exposed to certain drugs, even if there is a lack of adequate PK data or if limited data is available [75].

A study by Johnson et al. [76] used a pediatric PBPK model adjusted for physiological development, and CYP450 ontogeny to predict the clearance of 11 drugs in neonates, infants, and children [76]. Many of these studies evaluated their models by comparing the predicted data with the observed data. Comparison was made between drugs' clearance rates, volume of distribution, and elimination half-lives in both predicted and observed data. Predictions and observations were fairly close and within acceptable ranges for different age groups [71]. Such studies prove that PBPK can be adjusted for use with children, and that the addition of more parameters is also possible. Edginton and Willmann [77] in their study of liver cirrhosis adjusted a physiologybased model for liver volume and blood flow, plasma binding, enzymatic activity, and more parameters in accordance with the pediatric patient disease status and age group [77]. Edginton et al. [78], in another study, modified an adult PBPK model to serve as an age-dependent model useful for children aged $0-18$ years. This pediatric PBPK model used age-dependent physiological facts to scale for different age levels. Parameters used to scale for age are: cardiac output, portal vein flow, extracellular and total body water, and lipid and protein values [78].

Most of the PBPK models that were developed were based on intravenous (i.v.) administration of a drug. I.V. dose predictions were accurate and reliable. Unfortunately, this was not the case for oral or inhalational dosing. Oral dosing administration did not lead to reliable predictions for plasma concentrations and drugs' pharmacokinetics [71]. A group of researchers concluded that predictions of plasma doses through the i.v. route were $69 \%$ accurate, but were $23 \%$ accurate for oral routes [79]. Unfortunately, the estimates of inhalational routes may not be accurate; therefore PBPK models of environmental chemicals absorbed through inhalational routes are not yet ready to be used to predict respiratory diseases caused by inhalational exposures.

\section{Conclusion}

Children's continuous growth, differentiation, and maturation make them a different target population, for they are not simply small adults. Their physiochemical, biochemical, and pharmacokinetic features change during growth. Such developmental changes influence their susceptibility to environmental stressors, and thus their responses. This means that children at each age group have special characteristics which should be accounted for when assessing health outcomes, for instance: respiratory diseases. In addition, adjustment for children's measurements and parameters at different age groups must to be employed in risk assessment models when predicting health outcomes in children.

\section{References}

1. Walker JT, Walker OA (2000) A multiphasic approach for describing serial height data of Fels children: a hexaphasic-logistic-additive growth model. Growth Dev Aging 64: 33-49.

2. Haddad S, Restieri C, Krishnan K (2001) Characterization of age-related changes in body weight and organ weights from birth to adolescence in humans. J Toxicol Environ Health A 64: 453-464.

3. Price K, Haddad S, Krishnan K (2003) Physiological modeling of age-specific changes in the pharmacokinetics of organic chemicals in children. $\mathrm{J}$ Toxicol Environ Health A 66: 417-433.

4. Ginsberg GL, Foos BP, Firestone MP (2005) Review and analysis of inhalation dosimetry methods for application to children's risk assessment. J Toxicol Environ Health A 68: 573-615.

5. Becquemin, MM, Bertholon JF, Bouchikhi A, Malarbet JL, Roy M (1999)
Oronasal ventilation partitioning in adults and children: Effect on aeroso deposition in airways. Radiation Protection Dosimetry 81: 221-228.

6. James DS, Lambert WE, Mermier CM, Stidley CA, Chick TW, et al. (1997) Oronasal distribution of ventilation at different ages. Arch Environ Health 52 118-123.

7. Phalen RF, Oldham MJ, Mautz WJ (1989) Aerosol deposition in the nose as a function of body size. Health Phys 57 Suppl 1: 299-305.

8. Tabachnik E, Muller N, Toye B, Levison H (1981) Measurement of ventilation in children using the respiratory inductive plethysmograph. J Pediatr 99: 895-899.

9. Tobin MJ, Chadha TS, Jenouri G, Birch SJ, Gazeroglu HB, et al. (1983) Breathing patterns. 1. Normal subjects. Chest 84: 202-205.

10. Routledge PA (1994) Pharmacokinetics in children. J Antimicrob Chemother 34 Suppl A: 19-24.

11. Ginsberg G, Slikker W Jr, Bruckner J, Sonawane B (2004) Incorporating children's toxicokinetics into a risk framework. Environ Health Perspect 112: 272-283.

12. Dorne JL, Walton K, Renwick AG (2005) Human variability in xenobiotic metabolism and pathway-related uncertainty factors for chemical risk assessment: a review. Food Chem Toxicol 43: 203-216.

13. Landrigan PJ, Kimmel CA, Correa A, Eskenazi B (2004) Children's health and the environment: public health issues and challenges for risk assessment. Environ Health Perspect 112: 257-265.

14. Ginsberg G, Hattis D, Sonawane B, Russ A, Banati P, et al. (2002) Evaluation of child/adult pharmacokinetic differences from a database derived from the therapeutic drug literature. Toxicol Sci 66: 185-200.

15. Epstein LH, Wing RR, Cluss P, Fernstrom MH, Penner B, et al. (1989) Resting metabolic rate in lean and obese children: relationship to child and parent weight and percent-overweight change. Am J Clin Nutr 49: 331-336.

16. Guengerich FP (2008) Cytochrome p450 and chemical toxicology. Chem Res Toxicol 21: 70-83.

17. Barnes PJ (2013) Theophylline. Am J Respir Crit Care Med 188: 901-906.

18. Clewell HJ, Teeguarden J, McDonald T, Sarangapani R, Lawrence G, et al. (2002) Review and evaluation of the potential impact of age- and genderspecific pharmacokinetic differences on tissue dosimetry. Crit Rev Toxicol 32 329-389.

19. Kearns GL, Abdel-Rahman SM, Alander SW, Blowey DL, Leeder JS, et al. (2003) Developmental pharmacology--drug disposition, action, and therapy in infants and children. N Engl J Med 349: 1157-1167.

20. Alcorn J, McNamara PJ (2003) Pharmacokinetics in the newborn. Adv Drug Deliv Rev 55: 667-686

21. Anderson BJ, Holford NH (2013) Understanding dosing: children are small adults, neonates are immature children. Arch Dis Child 98: 737-744.

22. Dietert RR, Etzel RA, Chen D, Halonen M, Holladay SD, et al. (2000) Workshop to identify critical windows of exposure for children's health: immune and respiratory systems work group summary. Environ Health Perspect 108 Suppl 3: 483-490.

23. POTTER EL, LOOSLI CG (1951) Prenatal development of the human lung AMA Am J Dis Child 82: 226-228.

24. Boyden EA (1971) Development of the pulmonary airways. Minn Med 54: 894 897.

25. Foos B, Marty M, Schwartz J, Bennett W, Moya J, et al. (2008) Focusing on children's inhalation dosimetry and health effects for risk assessment: an introduction. J Toxicol Environ Health A 71: 149-165.

26. Moore KM (2013) The developing human clinically oriented embryology. In TVN Persaud and MG Torchia (Eds.), (9th edn). Philadelphia, PA. Saunders/ Elsevier.

27. Smiley-Jewell SM, Nishio SJ, Weir AJ, Plopper CG (1998) Neonatal Clara cell toxicity by 4 -ipomeanol alters bronchiolar organization in adult rabbits. Am J Physiol 274: L485-498.

28. Tyler WS, Tyler NK, Last JA, Gillespie MJ, Barstow TJ (1988) Comparison of daily and seasonal exposures of young monkeys to ozone. Toxicology 50 131-144. 
29. Joad JP, Bric JM, Peake JL, Pinkerton KE (1999) Perinatal exposure to aged and diluted sidestream cigarette smoke produces airway hyperresponsiveness in older rats. Toxicol Appl Pharmacol 155: 253-260.

30. Joad JP, Ji C, Kott KS, Bric JM, Pinkerton KE (1995) In utero and postnatal effects of sidestream cigarette smoke exposure on lung function, hyperresponsiveness, and neuroendocrine cells in rats. Toxicol Appl Pharmacol 132: 63-71.

31. Pereira LA, Loomis D, Conceição GM, Braga AL, Arcas RM, et al. (1998) Association between air pollution and intrauterine mortality in São Paulo, Brazil. Environ Health Perspect 106: 325-329.

32. Sagiv SK, Mendola P, Loomis D, Herring AH, Neas LM, et al. (2005) A timeseries analysis of air pollution and preterm birth in Pennsylvania, 1997-2001. Environ Health Perspect 113: 602-606.

33. Wilhelm M, Ritz B (2005) Local variations in CO and particulate air pollution and adverse birth outcomes in Los Angeles County, California, USA. Environ Health Perspect 113: 1212-1221.

34. Xu X, Ding H, Wang X (1995) Acute effects of total suspended particles and sulfur dioxides on preterm delivery: a community-based cohort study. Arch Environ Health 50: 407-415.

35. Bobak M (2000) Outdoor air pollution, low birth weight, and prematurity. Environ Health Perspect 108: 173-176.

36. Bobak M, Richards M, Wadsworth M (2001) Air pollution and birth weight in Britain in 1946. Epidemiology 12: 358-359.

37. Dejmek J, Selevan SG, Benes I, Solanský I, Srám RJ (1999) Fetal growth and maternal exposure to particulate matter during pregnancy. Environ Health Perspect 107: 475-480

38. Parker JD, Woodruff TJ, Basu R, Schoendorf KC (2005) Air pollution and birth weight among term infants in California. Pediatrics 115: 121-128.

39. Ritz B, Yu F (1999) The effect of ambient carbon monoxide on low birth weigh among children born in southern California between 1989 and 1993. Environ Health Perspect 107: 17-25.

40. Wang X, Ding H, Ryan L, Xu X (1997) Association between air pollution and low birth weight: a community-based study. Environ Health Perspect 105: 514-520.

41. Ahluwalia IB, Grummer-Strawn L, Scanlon KS (1997) Exposure to environmenta tobacco smoke and birth outcome: increased effects on pregnant women aged 30 years or older. Am J Epidemiol 146: 42-47.

42. Dejmek J, Solansky I, Podrazilova K, Sram RJ (2002) The exposure of nonsmoking and smoking mothers to environmental tobacco smoke during different gestational phases and fetal growth. Environmental Health Perspectives 110: 601-606.

43. Kharrazi M, DeLorenze GN, Kaufman FL, Eskenazi B, Bernert JT Jr, et al. (2004) Environmental tobacco smoke and pregnancy outcome. Epidemiology 15: $660-670$.

44. Schwartz J (1994) What are people dying of on high air pollution days? Environ Res 64: 26-35.

45. Ha EH, Lee JT, Kim H, Hong YC, Lee BE, et al. (2003) Infant susceptibility of mortality to air pollution in Seoul, South Korea. Pediatrics 111: 284-290.

46. Woodruff TJ, Grillo J, Schoendorf KC (1997) The relationship between selected causes of postneonatal infant mortality and particulate air pollution in the United States. Environmental Health Perspectives 105: 608-612.

47. Woodruff TJ, Parker JD, Schoendorf KC (2006) Fine particulate matter (PM2.5) air pollution and selected causes of postneonatal infant mortality in California. Environ Health Perspect 114: 786-790.

48. Bobak M, Leon DA (1999) The effect of air pollution on infant mortality appears specific for respiratory causes in the postneonatal period. Epidemiology 10 : 666-670.

49. Bobak M, Leon DA (1999) Pregnancy outcomes and outdoor air pollution: an ecological study in districts of the Czech Republic 1986-8. Occup Environ Med 56: $539-543$

50. Galizia A, Kinney PL (1999) Long-term residence in areas of high ozone: associations with respiratory health in a nationwide sample of nonsmoking young adults [dsee comments]. Environ Health Perspect 107: 675-679.

51. Gauderman WJ, Avol E, Gilliland F, Vora H, Thomas D, et al. (2004) The effect of air pollution on lung development from 10 to 18 years of age. N Engl J Med 351: 1057-1067.

52. Gent JF, Triche EW, Holford TR, Belanger K, Bracken MB, et al. (2003) Association of low-level ozone and fine particles with respiratory symptoms in children with asthma. JAMA 290: 1859-1867.

53. Lin M, Chen Y, Burnett RT, Villeneuve PJ, Krewski D (2002) The influence of ambient coarse particulate matter on asthma hospitalization in children: casecrossover and time-series analyses. Environ Health Perspect 110: 575-581.

54. Mar TF, Larson TV, Stier RA, Claiborn C, Koenig JQ (2004) An analysis of the association between respiratory symptoms in subjects with asthma and daily air pollution in Spokane, Washington. Inhal Toxicol 16: 809-815.

55. Sheppard L, Levy D, Norris G, Larson TV, Koenig JQ (1999) Effects of ambient air pollution on nonelderly asthma hospital admissions in Seattle, Washington 1987-1994. Epidemiology 10: 23-30.

56. Gilmour M, Jaakkola MS, London SJ, Nel AE, Rogers CA (2006) How exposure to environmental tobacco smoke, outdoor air pollutants, and increased pollen burdens influences the incidence of asthma. Environ Health Perspect 114: 627-633.

57. Erzurum SC, Gaston BM (2012) Biomarkers in asthma: a real hope to better manage asthma. Clin Chest Med 33: 459-471.

58. Szefler SJ, Wenzel S, Brown R, Erzurum SC, Fahy JV, et al. (2012) Asthma outcomes: Biomarkers. Journal of Allergy and Clinical Immunology, 129: S9S23.

59. McGwin G, Lienert J, Kennedy JI (2010) Formaldehyde exposure and asthma in children: a systematic review. Environ Health Perspect 118: 313-317.

60. Al-Daghri NM, Alokail MS, Abd-Alrahman SH, Draz HM, Yakout SM, et al (2013) Polycyclic aromatic hydrocarbon exposure and pediatric asthma in children: a case-control study. Environ Health 12: 1.

61. Spira-Cohen A, Chen LC, Kendall M, Lall R, Thurston GD (2011) Personal exposures to traffic-related air pollution and acute respiratory health among Bronx schoolchildren with asthma. Environ Health Perspect 119: 559-565.

62. Triche EW, Gent JF, Holford TR, Belanger K, Bracken MB, et al. (2006) Lowlevel ozone exposure and respiratory symptoms in infants. Environ Health Perspect 114: 911-916

63. Lin W, Huang W, Zhu T, Hu M, Brunekreef B, et al. (2011) Acute respiratory inflammation in children and black carbon in ambient air before and during the 2008 Beijing Olympics. Environ Health Perspect 119: 1507-1512.

64. Selgrade MK, Plopper CG, Gilmour MI, Conolly RB, Foos BS (2008) Assessing the health effects and risks associated with children's inhalation exposuresasthma and allergy. J Toxicol Environ Health A 71: 196-207.

65. (WHO) WHO (2010) Characterization and Application of Physiologically Based Pharmacokinetic Model in Risk Assessment. (IPCS harmonization project document no. 9). IPCS harmonization project.

66. Andersen ME (2003) Toxicokinetic modeling and its applications in chemical risk assessment. Toxicol Lett 138: 9-27.

67. Barton HA, Chiu WA, Setzer WR, Andersen ME, Bailer AJ, et al. (2007) Characterizing uncertainty and variability in physiologically based pharmacokinetic models: state of the science and needs for research and implementation. Toxicol Sci 99: 395-402.

68. Chiu WA, Barton HA, DeWoskin RS, Schlosser P, Thompson CM, et al. (2007) Evaluation of physiologically based pharmacokinetic models for use in risk assessment. J Appl Toxicol 27: 218-237.

69. Clewell RA, Clewell HJ 3rd (2008) Development and specification of physiologically based pharmacokinetic models for use in risk assessment. Regul Toxicol Pharmacol 50: 129-143.

70. Thompson CM, Johns DO, Sonawane B, Barton HA, Hattis D, et al. (2009) Database for physiologically based pharmacokinetic (PBPK) modeling physiological data for healthy and health-impaired elderly. J Toxicol Environ Health B Crit Rev 12: 1-24.

71. Barrett JS, Della Casa Alberighi O, Läer S, Meibohm B (2012) Physiologically based pharmacokinetic (PBPK) modeling in children. Clin Pharmacol Ther 92: $40-49$

72. Björkman S (2005) Prediction of drug disposition in infants and children by means of physiologically based pharmacokinetic (PBPK) modelling theophylline and midazolam as model drugs. Br J Clin Pharmacol 59: 691-704. 
73. Mouksassi MS, Marier JF, Cyran J, Vinks AA (2009) Clinical trial simulations in pediatric patients using realistic covariates: application to teduglutide, a glucagon-like peptide-2 analog in neonates and infants with short-bowe syndrome. Clin Pharmacol Ther 86: 667-671.

74. Ginsberg G, Hattis D, Russ A, Sonawane B (2004) Physiologically based pharmacokinetic (PBPK) modeling of caffeine and theophylline in neonates and adults: implications for assessing children's risks from environmental agents. J Toxicol Environ Health A 67: 297-329.

75. Jiang XL, Zhao P, Barrett JS, Lesko LJ, Schmidt S (2013) Application of physiologically based pharmacokinetic modeling to predict acetaminophen metabolism and pharmacokinetics in children. CPT Pharmacometrics Syst Pharmacol 2: e80.

76. Johnson TN, Rostami-Hodjegan A, Tucker GT (2006) Prediction of the clearance of eleven drugs and associated variability in neonates, infants and children. Clin Pharmacokinet 45: 931-956.

77. Edginton AN, Willmann S (2008) Physiology-based simulations of a pathological condition: prediction of pharmacokinetics in patients with liver cirrhosis. Clin Pharmacokinet 47: 743-752.

78. Edginton AN, Schmitt W, Willmann S (2006) Development and evaluation of a generic physiologically based pharmacokinetic model for children. Clin Pharmacokinet 45: 1013-1034.

79. Poulin P, Jones RD, Jones HM, Gibson CR, Rowland M, et al. (2011) PHRMA CPCDC initiative on predictive models of human pharmacokinetics, part 5: Prediction of plasma concentration-time profiles in human by using the physiologically-based pharmacokinetic modeling approach. J Pharm Sci 100 4127-4157. 